University of Wollongong

Research Online

Faculty of Engineering - Papers (Archive)

Faculty of Engineering and Information

Sciences

$1-1-2009$

\title{
Online performance evaluation of alternative control strategies for building cooling water systems prior to in-situ implementation
}

\author{
Zhenjun Ma \\ University of Wollongong, zhenjun@uow.edu.au \\ Shengwei Wang \\ The Hong Kong Polytechnic University \\ Fu Xiao \\ The Hong Kong Polytechnic University
}

Follow this and additional works at: https://ro.uow.edu.au/engpapers

Part of the Engineering Commons

https://ro.uow.edu.au/engpapers/920

\section{Recommended Citation}

Ma, Zhenjun; Wang, Shengwei; and Xiao, Fu: Online performance evaluation of alternative control strategies for building cooling water systems prior to in-situ implementation 2009, 712-721.

https://ro.uow.edu.au/engpapers/920 


\title{
Online Performance Evaluation of Alternative Control Strategies for Building Cooling Water Systems Prior to In-situ Implementation
}

\author{
Zhenjun MA, Shengwei WANG* and Fu Xiao \\ Department of Building Services Engineering, The Hong Kong Polytechnic University \\ Kowloon, Hong Kong \\ *Phone: (852) 2766-5858, Fax: (852) 2774-6146, Email: beswwang@polyu.edu.hk
}

\begin{abstract}
This paper presents the online test and evaluation of the performance of five practical control strategies (fixed set-point control method, fixed approach control method, two near optimal strategies and one optimal strategy) for building cooling water systems to identify the best strategy for future field validation. All of these strategies were tested and evaluated in a simulated virtual environment similar to the situation when they are actually implemented in practice. A virtual building system representing the real building and its central chilling system was developed and used to test the operational performance of the system controlled by different strategies. The packages of each control strategy are separately computed by the application program of Matlab, as the control optimizers to identify the necessary control settings for the given condition based on the collected operation data. The data exchanger between the virtual building system and the control optimizer was managed by a software platform through a communication interface. The results showed that the optimal control strategy is more energy efficient and cost effective than the other strategies, and its computational cost is manageable and can satisfy the
\end{abstract}


requirements of practical applications. This strategy is being implemented in a super highrise building for field validation.

Keywords: cooling water system, performance evaluation, control strategy, energy efficiency, communication interface

\section{Introduction}

Energy saving and $\mathrm{CO}_{2}$ emission reduction are among the most important issues receiving international attention. An increased awareness of these issues has motivated the practitioners in the HVAC (heating, ventilating, and air-conditioning) field to apply the most advanced design philosophies and extensive control strategies for HVAC systems to enhance their energy efficiency and provide robust operational performance. Cooling water systems as the major function components of building HVAC systems, often contribute significant portions to the total energy consumptions of overall HVAC systems [1]. Therefore, proper and optimal control the operation of cooling water systems has significant impacts on energy efficiency of buildings besides proper system designs and selection and maintenance of individual components.

To achieve efficient and reliable control and operation of HVAC systems in practice, two essential issues should be considered carefully prior to in-situ implementation of the control strategies. One is to select/develop the proper control strategy and the other is to test and evaluate the control performance and economic feasibilities of the control strategy by means of appropriate test methods.

During the past two decades, many researchers and experts in the HVAC field have devoted considerable efforts on energy efficient control and operation of building cooling water systems. These efforts have resulted in a number of near optimal and optimal control 
strategies readily available in literature [1-7]. Among the existing control strategies, two basic strategies are the fixed set-point control method and the fixed approach control method $[2,3]$. The fixed set-point control method is to vary the cooling tower air flow rate to maintain a constant condenser water supply temperature set-point while the fixed approach control method is to vary the cooling tower air flow rate to maintain a constant temperature difference between the cooling tower outlet water temperature and ambient air wet-bulb temperature. Several near optimal control strategies have been proposed to determine a near optimal condenser water supply temperature set-point, and then utilize this temperature set-point to approximately control the operation of cooling towers $[2,4,5]$. These strategies are commonly simple enough and easy to implement in practice. However, they cannot provide the true optimal settings, which might provide the settings significantly different from the optimal values, and a significant amount of energy might still be wasted. To maximize the operating efficiency of cooling water systems, several optimal control strategies have been developed [1,6,7]. Some of these strategies $[1,6]$ used global optimization techniques to systematically optimize the operation of cooling water systems, and some of them [7] aimed at operating cooling water systems economically as possible while still satisfying the constraints and requirements of practical applications, i.e., computational cost, control stability, etc. The performance tests of these strategies showed that a substantial amount of energy in cooling water systems can be saved when such strategies are used.

To determine the best strategy among the existing strategies with high promises to be used in practice, the control, environmental and energy performance of the selected promising strategies are better to be tested and analyzed carefully prior to field validation. 
To properly test and evaluate the performance of control strategies before in-situ validation, great efforts have been made on the construction of the virtual building systems [8-11], and the development of feasible test methods [12-15]. The virtual building system representing the real building and its air-conditioning system is a valuable tool that can be used to test the performance of control strategies under dynamic working conditions, and has been widely used in assisting the building control applications $[5,8,9,16,21]$. In general, there are two methods, i.e., by means of emulation and simulation, that have been used to test and evaluate the performance of control strategies based on the virtual building systems. The application of the emulators to assess the performance of the real energy management and control systems (EMCSs) was well studied under the framework of the International Energy Agency (IEA) in a completed collaborative research project Annex 17. An emulator commonly consists of a virtual building system and a hardware interface that allows the virtual building system to be connected to a real control system [16]. The outputs of Annex 17 proved that the emulation is technically feasible for testing of the real EMCSs $[12,13]$. The control strategies can also be tested and evaluated by means of simulation. In this approach, various control strategies can be programmed and integrated into the virtual building systems directly to evaluate their operational performance [8-10]. Both approaches are flexible and convenient for testing the HVAC control strategies with a low cost.

This paper presents online performance testing and evaluation of five practical control strategies for building cooling water systems to identify the best strategy for future field validation. The selected strategies were tested as a manner similar to the way that they can be implemented in practice. This test method is somewhat different from the existing test 
methods of by means of emulation and simulation. The best strategy identified in this study is being implemented in a super high-rise building in Hong Kong for field validation.

\section{Building and System Description}

The building concerned is a super high-rise building of approximately $490 \mathrm{~m}$ height (currently the tallest building in Hong Kong) and $321,000 \mathrm{~m}^{2}$ of floor area. The building has a basement of four floors, a block building of six floors and a tower building of 98 floors. The basement is used mainly for parking. The block building from the ground floor to the fifth floor serves mainly as the commercial center including hotel ballrooms, shopping arcades, and arrival lobbies. The tower building is mainly for commercial offices and a six-star hotel on the upper floors. The schematic of the central cooling water system in this building is illustrated in Fig. 1.

Six identical high voltage $(10,000 \mathrm{~V})$ centrifugal chillers located on the sixth floor with the capacity of $7,230 \mathrm{~kW}$ each and the nominal power consumption of $1,270 \mathrm{~kW}$ each at full load condition are used to supply the chiller water at $5.5^{\circ} \mathrm{C}$. Each chiller is associated with one constant condenser water pump and one constant primary chilled water pump. Taking into consideration the winter plume abatement purposes, two types of evaporating cooling towers (named CTA tower and CTB tower, respectively) are used in this building. Each of the CTA towers (total of six) without heating coils has a heat rejection capacity of $5234 \mathrm{~kW}$ and a nominal power consumption of $152 \mathrm{~kW}$ at the design condition. The rated water flow rate and air flow rate of each CTA tower are $250 \mathrm{~L} / \mathrm{s}$ and $142.8 \mathrm{~m}^{3} / \mathrm{s}$, respectively. Each of the CTB towers (total of five) equipped with heating coils has a heat rejection capacity of $4061 \mathrm{~kW}$ and a nominal power consumption of $120 \mathrm{~kW}$ at the design condition. The rated water flow rate and air flow rate of each CTB tower are $194 \mathrm{~L} / \mathrm{s}$ and 
$115.5 \mathrm{~m}^{3} / \mathrm{s}$, respectively. All cooling towers are an in house type and the warmed water to be cooled falls freely from the water distribution basin on the top of the cooling tower down to the fill packing in the cooling towers to achieve heat and mass transfer between the water and air. All cooling towers are equipped with variable speed axial fans. The layout of both types of the cooling towers is illustrated in Fig. 2. The six CTA towers are installed as a group. The outdoor air is drawn into a common plenum through an intake air louver before entering the six CTA towers. The five CTB towers are installed as another group, and the outdoor air is drawn into another common plenum before entering these CTB towers. There is a large distance between the two groups of cooling towers due to the space restriction of the building. The operation sequence of the cooling towers in two groups is recommended as follows by considering the flow resistances in both separate common passages (plenum and air louver) for the CTA towers and CTB towers. When an even number of the cooling towers is needed, the operating numbers of the CTA towers and CTB towers are the same. When an odd number of the cooling towers is needed, the number of the CTA towers used is one more or one less than the number of the CTB towers used, depending on which combination results in less energy consumption.

\section{Description and Formulation of the Five Selected Control Strategies}

\subsection{Outline of the Five Control Strategies}

To determine the best strategy that can be implemented in practice for energy efficient control and operation of cooling water systems, five strategies considered simple enough are selected in this study. A brief description of these strategies is provided as follows.

Strategy \#1: Fixed Set-point Control Method 
The first strategy evaluated is the fixed set-point control method. In this strategy, the condenser water supply temperature set-point is often set at a coldest temperature to allow good efficiency of chillers. Usually, $18.3^{\circ} \mathrm{C}$ is suggested since most chillers can operate normally at light loads with this temperature set-point although an even more cold temperature set-point is possible [3]. This strategy maintains a predetermined temperature set-point by changing the operating number of cooling towers and/or varying the operating frequency of cooling tower fans. In this study, this temperature set-point was set as $18.3^{\circ} \mathrm{C}$.

\section{Strategy \#2: Fixed Approach Control Method}

The second strategy evaluated is the fixed approach control method. This strategy is to maintain a constant temperature difference (named approach) between the condenser water supply temperature set-point (i.e., the water temperature leaving the cooling tower) and ambient air wet-bulb temperature. Usually, the design approach is used. In this strategy, the ambient air wet-bulb temperature needs to be continuously monitored to derive the condenser water supply temperature set-point. This strategy intends to enhance the efficiencies of both chillers and cooling towers as possible to reduce the total power consumption of chillers and cooling towers. In this study, the design approach $\left(5^{\circ} \mathrm{C}\right)$ is used. Strategy \#3: A Near Optimal Strategy A

The third strategy evaluated is a near optimal strategy presented in Ref. [5]. In this strategy, the condenser water supply temperature set-point is expressed as a linear relationship of the ambient air wet-bulb temperature and the ratio of the building cooling load to the design total cooling capacity of the chillers, as shown in Eq. (1). The coefficients in the relationship can be regressed from the performance maps generated by 
complete simulations or by testing the system over a significant range of settings and operating conditions.

$$
T_{w, c d \text {,sup }}=h_{0}+h_{1} T_{w b}+h_{2}\left(Q_{e v} / Q_{e v, d e s}\right)
$$

\section{Strategy\#4: A Near Optimal Strategy B}

The forth strategy evaluated is a near optimal strategy presented in Ref. [4]. In this strategy, the condenser water supply temperature set-point is reset using an empirical formula as shown in Eq. (2), in which the condenser water supply temperature set-point is expressed in the form of a second-order polynomial in terms of the ambient air wet-bulb temperature. The coefficients in the formula can be regressed from its corresponding performance map.

$$
T_{w, c d, \text { sup }}=q_{0}+q_{1} T_{w b}+q_{2} T_{w b}^{2}
$$

\section{Strategy \#5: An Optimal Control Strategy}

The fifth strategy evaluated is an optimal control strategy developed for real-time applications [7]. This strategy is composed of the performance predictor, energy estimator (i.e., cost function), optimization technique and supervisory strategy. The performance predictor utilizes performance models to predict the system energy performance and environmental quality, as well as the system response to the changes of the control settings. The energy estimator and optimization technique are used to determine the energy efficient control settings that minimize the overall energy consumption. The supervisory strategy is employed to provide the final decision (i.e., set-points and operation modes) taken into account the operating constraints of practical applications, i.e., the time interval between changes of two sets of the control settings should avoid an alternating fashion of ON/OFF of the corresponding components, etc. 
A HQS (hybrid quick search) method as an optimization technique was developed and used to seek the optimal condenser water supply temperature set-point. In this HQS optimization technique, the near optimal strategy, as illustrated in Eq. (1), was used to determine a near optimal temperature set-point. This near optimal temperature set-point was then alternatively used as the search center to define a relatively narrow search range, as shown in Eq. (3). Based on this narrow search range defined, the exhaustive search method was then used to search for the global optimal settings with a proper increment (e.g., $0.1 \mathrm{~K})$. The optimization technique determined by this manner can find the global optimal solutions with a reliable manner while still satisfying the requirements and constraints of practical applications. It is noted that the efficiency and computational performance of this HQS method is affected strongly by the effectiveness of the near optimal strategy used.

$$
T_{w, c d \text {,sup }}^{n, o}-\Delta T \leq T_{w, c d \text {,sup }} \leq T_{w, c d \text {,sup }}^{n . o}+\Delta T
$$

It is worthy noticing that Strategies \#1-\#4 can only provide the condenser water supply temperature set-point. However, for a given temperature set-point, there always exist several possible operating combinations of the number of cooling towers in operation and their individual fan speeds that can control the system to operate at the desired temperature set-point. Therefore, Strategies \#1-\#4 need to be further designed to make them have capabilities to identify the best combination among all possible operating combinations of the number of cooling towers operating and their fan speeds at a given temperature setpoint.

Since different performance predictors, energy estimators and supervisory strategies may result in different prediction results although the working condition is the same, the performance predictor, energy estimator and supervisory strategy used to further design 
Strategies \#1-\#4 are the same as that used to design Strategy \#5, while the exhaustive search method as the optimization tool is used in Strategies \#1-\#4 to search for the most energy efficient combination of the number of cooling towers in operation and their fan speeds. The objective function, operating constraints, and performance models used to formulate these five strategies are presented in the subsequent sections.

\subsection{Definition of the Objective Function and Operating Constraints}

For any given cooling load and ambient air wet-bulb temperature, the cooling water system optimization is to minimize the instantaneous total power consumption of all energy consumers in the system. Since the condenser water pumps in the system under study are constant speed pumps and the operation of each pump is dedicated to the operation of the correlated chiller that it serves. Therefore, the optimization of this cooling water system is to minimize the instantaneous total power consumption of both chillers and cooling towers. The objective function for this system can be expressed as in Eq. (4).

In practice, the operation of the cooling water system has to obey a number of constraints, i.e., basic energy and mass balances, mechanical limitations, etc. The heat rejected in the cooling towers equals the heat absorbed by the cooling water from the chiller condensers, as shown in Eq. (5). The heat generated in the chiller condensers is assumed equal to the sum of the cooling load and the power consumed by the chiller compressors as expressed by Eq. (6). The cooling water is assumed to be distributed to each operating cooling tower evenly to allow all cooling towers to operate at good efficiency. For the CTA towers and CTB towers, the distributed water mass flow rates can be determined according to Eqs. (7) and (8), respectively. The search range of the operating number of cooling towers is bounded as Eq. (9), in which the minimum number approximately guarantees that 
the cooling water distributed to each cooling tower does not overflow from the water distribution basin on the top of the cooling towers, while the maximum number intends to reduce the maintenance costs and extend the service life of the cooling towers to some extent in the long run. It is worthy noticing that the cooling water system cannot always be controlled to operate at the low temperature set-point provided by Strategy \#1 (the fixed set-point method), and the maximum limit of the operating number of the cooling towers for Strategy \#1 is therefore further increased till to eleven if the predicted fan frequencies corresponding all possible operating numbers of the cooling towers defined by Eq. (9) exceed the design input frequency of the cooling tower fans. To avoid the low condenser water supply temperature set-point causing the low pressure problems in the chillers, the low limit of the condenser water supply temperature set-point is bounded to $18^{\circ} \mathrm{C}$. The input frequency to the cooling tower fans is bounded between $20 \mathrm{~Hz}$ and $50 \mathrm{~Hz}$.

$$
\begin{gathered}
J=\min _{T_{w, d d, s u p}} W_{t o t}=\sum_{k=1}^{N_{c h}} W_{c h, k}+\sum_{i=1}^{N_{c T A}} W_{C T A, i}+\sum_{j=1}^{N_{c T B}} W_{C T B, j} \\
\sum_{i=1}^{N_{C T A}} Q_{C T A, i}+\sum_{j=1}^{N_{c T B}} Q_{C T B, j}=\sum_{k=1}^{N_{c h}} Q_{c d, k} \\
\sum_{k=1}^{N_{c h}} Q_{c d, k}=\sum_{k=1}^{N_{c h}} Q_{e v, k}+\sum_{k=1}^{N_{c h}} W_{c o m p}, k \\
M_{w, C T A, i}=\frac{M_{w, C T A, d e s} \cdot \sum_{k=1}^{N_{c h}} M_{w, c d, k}}{M_{w, C T A, d e s} \cdot N_{C T A}+M_{w, C T B, d e s} \cdot N_{C T B}} \\
M_{w, C T B, j}=\frac{M_{w, C T B, d e s} \cdot \sum_{k=1}^{N_{c h}} M_{w, c d, k}}{M_{w, C T A, d e s} \cdot N_{C T A}+M_{w, C T B, d e s} \cdot N_{C T B}}
\end{gathered}
$$




$$
f i x\left(\sum_{k=1}^{N_{c h}} M_{w, c d, k} / M_{w, C T A, d e s}\right)+1 \leq N_{c t} \leq \min \left\{\left(2 N_{c h}+2\right), 11\right\}
$$

\subsection{Description of the System Performance Models Used}

Detailed physical models and purely data-driven models are not the proper choice for online control applications. In general, purely data-driven models cannot always ensure stable performance prediction although they are simple. Detailed physical models always require high computational costs and memory demands as well as a lot of iterations, which may seriously prevent their online control applications, although they are effective. For online applications, the models utilized in the control system preferably have simplified structures with certain physical significance to ensure stable performance prediction and acceptable accuracy over a wide range of operation conditions. The models should also require less calibration efforts with readily available operation data, less computational costs and memory demands [17]. In this study, a simplified chiller model and a simplified cooling tower model were used to design the five control strategies.

\subsubsection{Simplified Chiller Model}

The chiller model utilized is developed based on the fundamental principles of thermodynamic and the heat/mass transfer processes in the chillers [7]. A fictitious refrigeration cycle $\left(1^{\prime}-2^{\prime}-3^{\prime}-4^{\prime}\right)$, as shown in Fig. 3, is assumed to simplify the complicated thermodynamic processes occurring in the refrigeration system. The chiller evaporator and condenser are simulated using the classical heat exchanger efficiency method. The overall heat transfer coefficients of the evaporator and condenser are represented empirically as Eqs. (10) and (11), respectively. The fictitious refrigerant mass flow rate is calculated as Eq. (12), which is based on the actual evaporator cooling energy and the enthalpy difference between the fictitious point $1^{\prime}$ and point $3^{\prime}$ in the fictitious cycle. The fictitious power, as in 
Eq. (13), is the product of the fictitious refrigerant mass flow rate and the enthalpy difference between point $2^{\prime}$ and point $1^{\prime}$ in the fictitious refrigeration cycle. An empirical polynomial as in Eq. (14) is used to characterize the relationship between the actual chiller power consumption and the fictitious power consumption.

$$
\begin{gathered}
C_{1} M_{w, e v}{ }^{-0.8}+C_{2} Q_{e v}{ }^{-0.745}+C_{3}=\frac{1}{U A_{e v}} \\
C_{4} M_{w, c d}^{-0.8}+C_{5}\left(Q_{e v}+W_{c o m p}\right)^{1 / 3}+C_{6}=\frac{1}{U A_{c d}} \\
M_{r e f, f i c}=\frac{Q_{e v}}{h_{1}^{\prime}-h_{3}^{\prime}} \\
W_{f i c}=M_{r e f, f i c} \cdot\left(h_{2}^{\prime}-h_{1}^{\prime}\right) \\
W_{c o m p}=a_{0}+a_{1} W_{f i c}+a_{2} W_{f i c}^{2}
\end{gathered}
$$

\subsubsection{Simplified Cooling Tower model}

The cooling tower model utilized is the so-called "Toolkit model" [18]. In this model, the cooling tower was modeled as an equivalent heat exchanger. In terms of the fundamental laws of heat and mass transfer phenomena occurring in the cooling tower, the energy balances on the air side and water side can be computed using Eqs. (15) and (16), respectively. The heat transfer between the water and air is simulated using Eq. (17). Since both the air flow rate and water flow rate flowing through the cooling towers can be varied, the number of transfer unit (NTU) is modified and computed using Eq. (18). The water temperature leaving the cooling towers can be calculated through the energy balance on the water side. The fan operating frequency and power consumption can be predicted using empirical formulas as shown in Eqs. (19) and (20), respectively.

$$
Q=M_{a} \cdot\left(h_{a, o}-h_{a, i}\right)
$$




$$
\begin{gathered}
Q=M_{w} \cdot c_{p, w} \cdot\left(T_{w, i}-T_{w, o}\right) \\
Q=\varepsilon_{f i c} \cdot C_{\min } \cdot\left(T_{w, i}-T_{w b, i}\right) \\
N T U=b_{0}\left(\frac{M_{w}}{M_{a}}\right)^{b_{1}} \\
\text { Freq } q_{c t}=\text { Freq }_{c t, d e s}\left(e_{0}+e_{1}\left(\frac{M_{a}}{M_{a, d e s}}\right)+e_{2}\left(\frac{M_{a}}{M_{a, d e s}}\right)^{2}\right) \\
W_{c t}=W_{c t, d e s}\left(g_{0}+g_{1}\left(\frac{\text { Freq }}{\text { Freq }_{c t, d e s}}\right)+g_{2}\left(\frac{\text { Freq }}{\text { Feeq }_{c t, d e s}}\right)^{2}\right)
\end{gathered}
$$

For the application of this model, the outlet variables are obtained in an iterative manner by initially assuming a temperature difference of $5^{\circ} \mathrm{C}$ between the inlet and outlet air wetbulb temperatures.

\section{Descriptions of the Virtual Building System and Communication Platform}

\subsection{Description of the Virtual Building System}

A virtual building system representing the real building and its central chilling system was constructed for energy performance study and for testing the performance of alternative control strategies [10]. This system was constructed based on a transient simulation program TRNSYS [19]. It was originally constructed using the similar way as the virtual systems constructed in Refs. [8,9], in which all controllers, major component models and their interconnections are programmed and integrated into the same simulation environment. In order to test the performance of the control strategies as a manner similar to the way that they will be implemented in practice, all controllers except PID controllers are separated from the virtual building system and they are complied as a separate package under Matlab environment. This package will act as the control optimizer providing the 
control settings for the virtual building system managed by a communication platform via an interface. Since the construction of the virtual building systems has been well presented in a number of studies $[8,9,11]$, the detailed description of the construction of this virtual building system is not provided here. Since the chiller and cooling tower models play significant roles in the virtual building system to test and evaluate the performance of alternative control strategies for cooling water systems, a brief summary of both models is provided here below. It is worthwhile to note that the models used in the virtual building systems could be very detailed to well represent the real systems, which is significantly different from the models used by the online control strategies.

\subsubsection{Chiller Model Used in the Virtual Building System}

The chiller model used to construct the virtual building system is a detailed physical model presented in Ref. [8]. This model simulates the chiller performance dynamically under various working conditions on the basis of the impeller tip speed $\left(u_{2}\right)$, impeller exhaust area $(A)$, impeller blades angle $(\beta)$ and other coefficients/constants. The simulation mainly involves the compressor, condenser, evaporator and motor power consumption, as well as the thermal capacitances of the components associated with the heat transfer in the chiller. The compressor is modeled on the basis of mass conservation, Euler turbo-machine equation and energy balance equation. The Euler equation is modified by considering the impeller exit radial velocity $\left(\mathrm{c}_{\mathrm{r} 2}\right)$ distribution and derived as in Eq. (21). Energy balance equations are applied to the compressor control volume and impeller control volume resulting in Eqs. (22) and (23), respectively. The hydrodynamic losses in the two control volumes are considered to be composed of three elements as in Eqs. (24) and (25), respectively. 


$$
\begin{gathered}
h_{t h}=u_{2}\left[u_{2}-\left(\frac{\pi^{2}}{8}\right)^{2} c_{r 2}\left(\operatorname{ctg} \beta+B \frac{v_{1}}{v_{i}} \operatorname{tg} \theta\right)\right] \\
h_{t h}=h_{\text {pol.comp }}+h_{\text {hyd.comp }} \\
h_{\text {th }}=h_{\text {pol.imp }}+h_{\text {hyd.imp }}+\frac{c_{i}^{2}}{2} \\
h_{\text {hyd.comp }}=\zeta\left[1+\psi_{1}\left(\frac{v_{1}}{v_{i}} \frac{1}{\cos \theta}\right)^{2}+\psi_{2}\left(\frac{v_{1}}{v_{i}} \operatorname{tg} \theta\right)^{2}\right] c_{r 2}^{2} \\
h_{\text {hyd.imp }}=\zeta\left[\chi+\psi_{1}\left(\frac{v_{1}}{v_{i}} \frac{1}{\cos \theta}\right)^{2}+\psi_{2}\left(\frac{v_{1}}{v_{i}} \operatorname{tg} \theta\right)^{2}\right] c_{r 2}^{2}
\end{gathered}
$$

Given the evaporator pressure, condenser pressure and inlet guide vane angle, the compressor model can calculate the radial velocity and specific volume at the impeller exhaust and, thus, the refrigerant mass flow rate and internal power. The evaporator and condenser are simulated using the classical heat exchanger efficiency method. The chiller power consumption is calculated on the basis of the internal compression power $\left(P_{\text {inter }}\right)$, as shown in Eq. (26).

$$
W_{\text {comp }}=\alpha W_{\text {inter }}+W_{l}
$$

\subsubsection{Cooling Tower Model Used in the Virtual Building System}

The cooling tower model used to construct the virtual building system is the effectiveness model presented in Ref. [20]. This model utilizes the effectiveness relationship developed for sensible heat exchangers by introducing an air saturation specific heat and a modified definition of the number of transfer units. Based on the steady-state energy and mass balances on an incremental volume, the differential equations, as shown in Eqs. (27)-(29), can be derived. The effectiveness of the cooling tower $\left(\varepsilon_{a}\right)$ is used to 
simulate the heat and mass transfer processes in the cooling tower and the actual heat transfer is then calculated in terms of this effectiveness as in Eq. (30). The outlet air and water states are computed through the overall energy balances as in Eqs. (31)-(33). The power consumption of the cooling tower is simulated using the same equation as expressed in Eq. (20).

$$
\begin{gathered}
\frac{d \omega_{a}}{d V}=-\frac{N T U}{V_{T}}\left(\omega_{a}-\omega_{s, w}\right) \\
\frac{d h_{a}}{d V}=-L e \frac{N T U}{V_{T}}\left[\left(h_{a}-h_{s, w}\right)+\left(\omega_{a}-\omega_{s, w}\right)(1 / L e-1) h_{g, w}\right] \\
\frac{d T_{w}}{d V}=\frac{d h_{a} / d V-c_{p, w}\left(T_{w}-T_{r e f}\right) d \omega_{a} / d V}{\left[M_{w, i} / M_{a}-\left(\omega_{a, o}-\omega_{a}\right)\right] c_{p, w}} \\
Q=\varepsilon_{a} M_{a}\left(h_{s, w, i}-h_{a, i}\right) \\
h_{a, o}=h_{a, i}+\varepsilon_{a}\left(h_{s, w, i}-h_{a, i}\right) \\
\omega_{a, o}=\omega_{s, w, e}+\left(\omega_{a, i}-\omega_{s, w, e}\right) \exp (-N T U) \\
T_{w, o}=T_{r e f}+\frac{M_{w, i}\left(T_{w, i}-T_{r e f}\right) c_{p, w}-M_{a}\left(h_{a, o}-h_{a, i}\right)}{M_{w, o} c_{p, w}}
\end{gathered}
$$

\subsection{Description of the Communication Platform}

The communication platform is developed on the basis of IBmanager. IBmanager is an open intelligent building integration and management platform based on middleware and Web services technologies to support the integration and management of BASs (building automation systems) from different vendors, as well as remote monitoring and management services. It provides a convenient platform for integrating full scale building automation and industrial automation (IA) systems. IBmanager can be used to integrate various subsystems, including BA (building automation) control stations, BA systems and network 
communication and information management. It provides relevant software platform for the development and implementation of supervision, management and customized strategies. IBmanager supports the customized development of various IB subsystems. Fig. 4 illustrates the system architecture of the communication platform based on IBmanager, which includes the client side and server side. The client side is mainly the human machine interface with functions of supervisory displays and the access on configuration database and historical database based on ASP (Active Server Pages). In the server side, IBserver realizes real-time data access, weather information access, configuration data access, and historical data access, as well as data format transformation and data distribution. In this study, this communication platform is used to achieve the data exchanger between the package of the control strategy and the virtual building system through a file point driver. For in-situ implementation, the package of the control strategy will communicate with the BAS by means of this communication platform through a proper interface, i.e., BACnet driver, OPC or XML driver, etc.

\section{Performance Test and Evaluation of Control Strategies}

Since the building under study is still at the construction stage, the hourly-based annual building cooling load profiles of this building were calculated using EnergyPlus based on the design data and hourly-based weather data for the typical year in Hong Kong. The hourly-based annual ambient wet-bulb and dry-bulb temperature profiles in the typical year in Hong Kong are shown in Fig. 5. In this study, a simple chiller sequence strategy was used to control the operation of the chillers. Using this strategy, one more chiller is switched on when the operating chillers are fully loaded and one of the operating chillers is switched off when the remaining chillers can handle the current building cooling load. For 
Strategy \#5, the search range in Eq. (3) was bounded within $\pm 2.0 \mathrm{~K}$ and the exhaustive search method found the global optimal solutions within the limited search range with a 0.1 $\mathrm{K}$ increment.

\subsection{Setup of the Tests}

The overall test and evaluation platform of the control strategies is illustrated in Fig. 6. The virtual building system is used to represent the real building and its central chilling system to produce the status data (i.e., online operation data), while the package of the control strategy acting as the control optimizer is computed by Matlab and complied as a DLL (dynamic link library) module invoked by IBmanager. During the tests, the building cooling load and weather data including air wet-bulb temperature, air dry-bulb temperature were provided via a data file to the virtual building system. The online measurements, including the number of chillers in operation, outdoor air dry-bulb and wet-bulb temperatures, the chilled water supply and return temperatures, which represent the current working condition of the cooling water system, are collected from the virtual building system and then transferred to the control optimizer by the communication platform for control supervision. The control optimizer seeks the most energy efficient control settings (i.e., the number of CTA towers operating, the number of CTB towers operating, and the condenser water supply temperature set-point) for the given condition according to the received status data and then transferred these control settings to the virtual building system through the communication platform to achieve energy efficient control and operation.

\subsection{Training of the Near Optimal Control Strategies}

To evaluate the performance of different control strategies, the coefficients in Strategies \#3 and \#4 need to be identified firstly. Using the performance models, cost function and 
operating constraints presented previously, a model-based control strategy using the exhaustive method as the optimization tool can be easily designed. Using this model-based control strategy, the hourly-based optimal condenser water supply temperature set-points for all working conditions in the whole year operation of that building can be simulated based on the hourly-based whole year building cooling loads and hourly-based weather data, within a wide search range of the condenser water supply temperature set-point (low limit is $18^{\circ} \mathrm{C}$, and upper limit is $34^{\circ} \mathrm{C}$ ) and with an increment of $0.1 \mathrm{~K}$. Two performance maps associated with major variables for Strategies \#3 and \#4 can then be generated using these identified optimal condenser water supply temperature set-points and the coefficients in Eqs. (1) and (2) can then be identified. The regression using the least-square regression method gives that the coefficients in Eq. (1) are: $h_{0}=11.0305, h_{1}=0.6887$, and $h_{2}=2.9939$ with the coefficient of determination $\mathrm{R}^{2}$ of 0.9819 , and the coefficients in Eq. (2) are: $q_{0}=15.3958, q_{1}=0.1476, q_{2}=0.0197$ with the coefficient of determination $\mathrm{R}^{2}$ of 0.9526 .

\subsection{Test and Evaluation of the Five Control Strategies}

In the following two exercises, the performance of the five control strategies was tested and evaluated in terms of their control accuracy, computational performance and energy performance.

\section{Exercise 1: Test and Evaluation of Control Accuracy and Computational Performance}

In this exercise, the control accuracy and computational performance of the five control strategies were tested and evaluated using two typical data points: one is the spring case and the other is the sunny-summer case. By comparing the power consumption predicted by each control strategy with the corresponding power consumption 'measured' from the 
virtual building system resulted by the application of the control settings identified by each strategy, the effectiveness and efficiency of each control strategy can be evaluated.

Table 1 summarizes the identified control settings and predicted power consumption as well as the online measurements collected from the virtual building system using the control settings identified by each control strategy in the two typical cases. It can be found that the operating numbers of CTA towers and CTB towers identified by the five strategies for two cases are the same, but the temperature set-points are significantly different, causing that the fan operating frequencies are different. Among the five control strategies, the identified temperature set-points, and predicted and 'measured' power consumptions of the chillers and cooling towers using Strategies \#3, \#4 and \#5 are very similar. These three strategies also consumed the least energy as compared with that of Strategies \#1 and \#2 according to both predicted and measured power consumptions. It also can be observed that the power consumptions predicted by each strategy agreed well with that of their corresponding measurements collected from the virtual building system although they are some deviations existed between two sets of power consumptions due to the model prediction. However, such deviations are acceptable for practical applications.

In the sunny-summer case, the outdoor air temperature and building cooling load are relatively higher, and the virtual building system cannot be controlled to operate at the low temperature set-point provided by Strategy \#1. Therefore, the control optimizer can only predict that all towers need to be operated at their design frequencies, but the power consumption of the chillers cannot be predicted in that the actual condenser water supply temperature is unknown. When using this low temperature set-point to practically control 
the operation of the virtual building system, the actual temperature that can be reached was $27.24^{\circ} \mathrm{C}$.

The computational costs of the five control strategies were tested to evaluate their computational performance for practical applications. The tests were conducted under the Matlab environment with the same computer and the results are presented in Table 1 as well. The computer configurations used in the tests are described as follows. The operation system is the Microsoft windows XP professional, and the processor is the $\operatorname{Intel}(\mathrm{R})$ Pentium(R) 4 CPU $3.20 \mathrm{GHz}$ (2 CPUs), and the memory is 2040MB RAM. The average computational costs required by the five strategies varied from $0.132 \mathrm{~s}$ to $0.152 \mathrm{~s}$ for the sunny-summer case and from $0.137 \mathrm{~s}$ to 0.175 s for the spring case, which demonstrates that the computation costs of these five strategies are generally manageable and can satisfy the requirements of practical applications.

Due to the strategies were tested as a manner similar to situation when they are actually implemented in practice, the above results also demonstrate the effectiveness of this test method for evaluating the performance of alternative control strategies prior to in-situ implementation.

\section{Exercise 2: Test and Evaluation of Energy Performance}

In this case, two typical days, which represent the typical operation condition of the airconditioning system in the spring and sunny-summer, respectively, were selected to test and evaluate energy performance of the five control strategies. In the following study, the performance of Strategy \#1 was used as the benchmark for comparisons.

Table 2 presents the online measured and predicted daily power consumptions of the chillers and cooling towers using the five different strategies in the two typical days. Due to 
the same reason as presented in Exercise 1, the power consumption using Strategy \#1 cannot be predicted and, therefore, is not provided in Table 2. Compared with the online measured power consumption using the control settings of Strategy \#1, about $6,899.6 \mathrm{kWh}$ $(10.79 \%)$ and $23,852.0 \mathrm{kWh}(21.27 \%)$ energy can be saved when using the control settings provided by Strategy \#2, while about 9,413.1 kWh (14.73\%) and 24,733.6 kWh (22.05\%) energy can be saved when using the settings provided by Strategy \#3 in the typical spring day and sunny-summer day, respectively. It also can be found that Strategy \#4 saved about 9,169.6 kWh (14.35\%) and 24,779.6 kWh (22.09\%) energy while Strategy \#5 saved about 9,481.4 kWh (14.83\%) and 24,856.9 kWh (22.16\%) energy in the typical spring day and sunny-summer day respectively, as compared with that using the settings of Strategy \#1. Among these five strategies, Strategy \#5 is the most energy efficient and cost effective.

It is noted that the differences between the online measured power consumptions and predicted power consumptions using the five control strategies are within $1.31 \%-1.84 \%$ and within $2.43 \%-2.84 \%$ in the typical spring day and sunny-summer day, respectively. It is expected that the actual differences in practical applications might be smaller than that presented in this paper since the models used in the control system and virtual building system are different and both types of models have their own prediction deviations although they are trained using the same performance data.

Figs. 7 and 8 present the profiles of the online measured water temperature leaving cooling towers from the virtual building system using the control settings provided by different control strategies in the typical spring day and sunny-summer day respectively. It can be found that the measured temperatures using different strategies are significantly different. It is worthy pointing out that the cooling water system can always be controlled to 
operate at the temperature set-points provided by Strategies \#2-\#5. However, the system cannot always be controlled to operate at the low temperature set-point provided by Strategy \#1, especially in the typical sunny-summer day. The large difference between the measured water temperature leaving cooling towers and the fixed temperature set-point provided by Strategy \#1 further verified the ineffectiveness of this strategy.

Figs. 9 and 10 present the differences of the hourly-based measured power consumptions between Strategies \#2-\#5 and Strategy \#1 in the typical spring day and sunny-summer day, respectively. It can be observed that a substantial amount of energy can be saved when Strategies \#2-\#5 are used as compared with that using Strategy \#1. It also can be found that Strategies \#3, \#4 and \#5 can save more energy than that of Strategy \#2. It is of interest to note that the power saving profiles in the typical spring day and sunnysummer day are significantly different. The reason is that the cooling water system was never controlled to operate at the low temperature set-point provided by Strategy \#1 in the typical sunny-summer day due to the higher ambient air wet-bulb temperatures, which results that all cooling towers were operated at their design frequencies even though the cooling load requirement is still relatively low.

Based on the above study, it can be concluded that Strategy \#5 is the most promising strategy while Strategies \#3 and \#4 are also the energy efficient and cost effective strategies. These there strategies are still simple and easy to implement in practice.

\section{Conclusion}

This paper presents the online testing and evaluation of the performance of five practical strategies for cooling water systems to identify the best strategy for later field implementation and validation. These strategies were tested against a virtual building 
system. To the control strategies and software, the test environment is similar to the situation when they are actually implemented in real buildings. The test results showed that all these five strategies have satisfactory computational performance for practical applications. The optimal control strategy (Strategy \#5) is the most promising strategy among the selected strategies while two near optimal strategies (Strategies \#3 and \#4) are also energy efficient and cost effective as compared with the fixed set-point control method (Strategy \#1) and the fixed approach control method (Strategy \#2). It is worthy noticing that near optimal strategies can only provide the condenser water supply temperature setpoint, but they cannot provide the best operating combination of the number of cooling towers in operation and their individual fan speeds that can control the system to operate at the desired temperature set-point. Therefore, the near optimal strategies should be further designed to enhance the operating efficiency of cooling water systems if they are considered to be used in practice. The tests results also demonstrate that the test method used in this study is technically feasible and effective to evaluate the performance of alternative control strategies prior to in-situ implementation. The most promising strategy (Strategy \#5) identified in this study is being implemented in a super high-rise building in Hong Kong for field application and validation.

\section{Acknowledgements}

The research work presented in this paper is financially supported by a grant of the Research Grant Council (RGC) of the Hong Kong SAR and the support of Sun Hung Kai Real Properties Limited. The authors would like to thank Mr. W. K. Pau, Sun Hung Kai Real Properties Limited for his essential support to the research work. 


\section{Nomenclature}

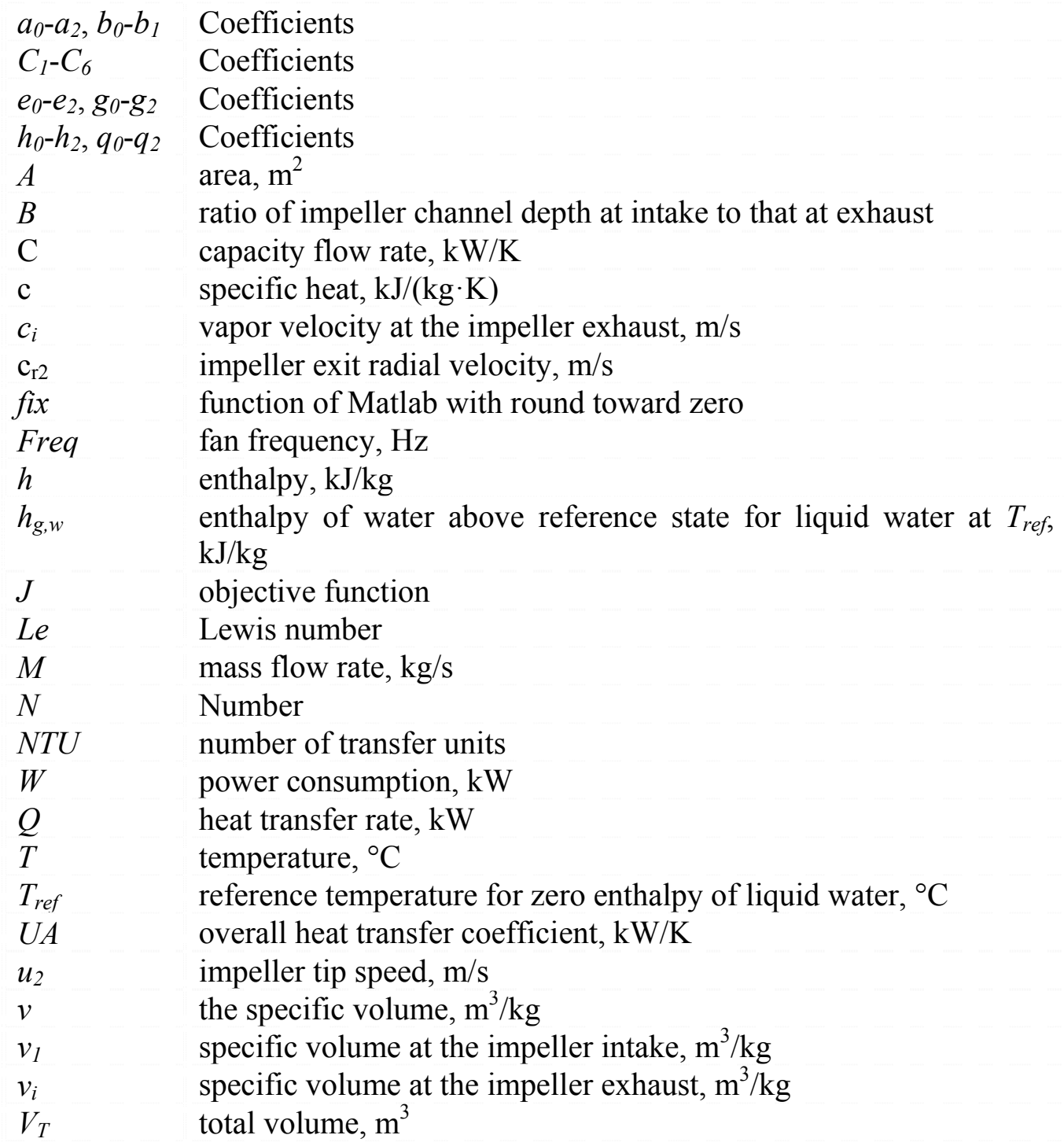

\section{Greek symbols}

$\begin{array}{ll}\alpha & \text { Coefficient } \\ \beta & \text { impeller blades angle } \\ \varepsilon & \text { heat transfer effectiveness } \\ \omega & \text { air humidity ratio } \\ \theta & \text { inlet guide vane angle } \\ \zeta, \chi & \text { Constants } \\ \psi_{1}, \psi_{2} & \text { Constants }\end{array}$

\section{Subscripts}

$a$

$c d$
Air

Condenser 


$\begin{array}{ll}\text { ch } & \text { Chiller } \\ \text { comp } & \text { Compressor } \\ c t & \text { cooling tower } \\ \text { CTA } & \text { CTA tower } \\ C T B & \text { CTB tower } \\ d e s & \text { design } \\ e & \text { Effective } \\ e v & \text { Evaporator } \\ \text { fic } & \text { Fictitious } \\ h y d & \text { Hydrodynamic } \\ \text { imp } & \text { Impeller } \\ i & \text { Inlet } \\ \text { inter } & \text { Internal } \\ l & \text { Loss } \\ o & \text { Outlet } \\ p & \text { Pressure } \\ \text { pol } & \text { Polytropic } \\ r e f & \text { Refrigerant } \\ s & \text { Saturation } \\ s u p & \text { Supply } \\ t h & \text { Theoretical } \\ \text { tot } & \text { Total } \\ w & \text { Water } \\ w b & \text { wet-bulb } \\ \end{array}$

Subscripts

$\begin{array}{ll}n & \text { Near } \\ o & \text { Optimal }\end{array}$

\section{References}

[1] Lu L, Cai WJ, Xie LX, Li SJ, Soh YC. HVAC system optimization-condenser water loop. Energy Conversion and Management 2004;45(4):613-30.

[2] Braun JE, Diderrich GT. Near-optimal control of cooling towers for chilled-water systems. ASHRAE Transactions 1990;96(2):806-13.

[3] Crowther H, Furlong J. Optimizing chillers \& Towers. ASHRAE Journal 2004;46(7):34-44.

[4] Yao Y, Lian ZW, Hou ZJ, Zhou XJ. Optimal operation of a large cooling system based on empirical model. Applied Thermal Engineering 2004;24(16):2303-21.

[5] Sun J, Reddy A. Optimal control of building HVAC\&R systems using complete simulation-based sequential quadratic programming (CSB-SQP). Building and 
Environment 2005;40(5):657-69.

[6] Koeppel EA, Klein SA, Mitchell JW, Flake BA. Optimal supervisory control of an absorption chiller system. HVAC\&R Research 1995;1(4):325-42.

[7] Ma ZJ, Wang SW, Xu XH, Xiao F. A supervisory control strategy for building cooling water systems for practical and real time applications. Energy Conversion and Management, 2008;doi:10.1016/j.enconman.2008.01.019.

[8] Wang SW. Dynamic simulation of building central chilling system and evaluation of EMCS on-Line control strategies. Building and Environment 1998;33(1):1-20.

[9] Wang SW. Dynamic simulation of building VAV air-conditioning system and evaluation of EMCS on-line control. Building and Environment 1999;34(6):681705

[10] Wang SW, Xu XH, Ma ZJ. Report on the energy performance evaluation of International Commerce Center (ICC), Hong Kong. The Hong Kong Polytechnic University; 2006.

[11] Husaunndee A, Visier JC. Building HVAC system in control engineering--a modeling approach in a widespread graphical environment. ASHRAE Transactions 1999;105(1):319-29.

[12] Annex17. Simulation and emulation of HVAC systems-Meeting in Lige, CSTB Research Notes, CSTB Reference: GEC/DGE 930.9R, CSTB, France; 1992.

[13] Annex17. Development of emulation methods. VTT Research Notes, ISBN 95138-448-X; 1993.

[14] Kärki SH, Lappalainen VE. A new emulator and a method for using it to evaluate BEMS. ASHRAE Transactions 1994;100(1):1494-503.

[15] Lahrech R, Gruber P, Riederer P, Tessier P, Visier JC. Development of a testing method for control HVAC systems by emulation. Energy and Buildings 2002;34:909-16.

[16] Peitsman, HC, Wang SW, Kärki SH, Park C, Haves P. The reproducibility of tests on energy management and control system using building emulators. ASHRAE Transactions 1994;100(1):1455-63.

[17] Wang SW, Ma ZJ. Supervisory and optimal control of building HVAC systems: A review. HVAC\&R Research 2008;14(1):3-32. 
[18] Lebrun J. A Toolkit for primary HVAC energy calculations. ASHRAE inc.: Altanta, USA; 1993.

[19] Klein SA. Hughes PJ, Theilacker JC, Beckman WA, Eberlein ME, Morrison GL, et al.. TRNSYS, a Transient Simulation Program. University of WisconsinMadison, USA: Solar Energy Laboratory, Version 13.1; 1990.

[20] Braun JE, Klein SA, Mitchell JM. Effectiveness models for cooling towers and cooling coils. ASHRAE Transactions 1989;95(2):164-74.

[21] Jin XQ, Du ZM, Xiao XK. Energy evaluation of optimal control strategies for central VWV chiller systems. Applied Thermal Engineering 2007;27 (5-6):934941.

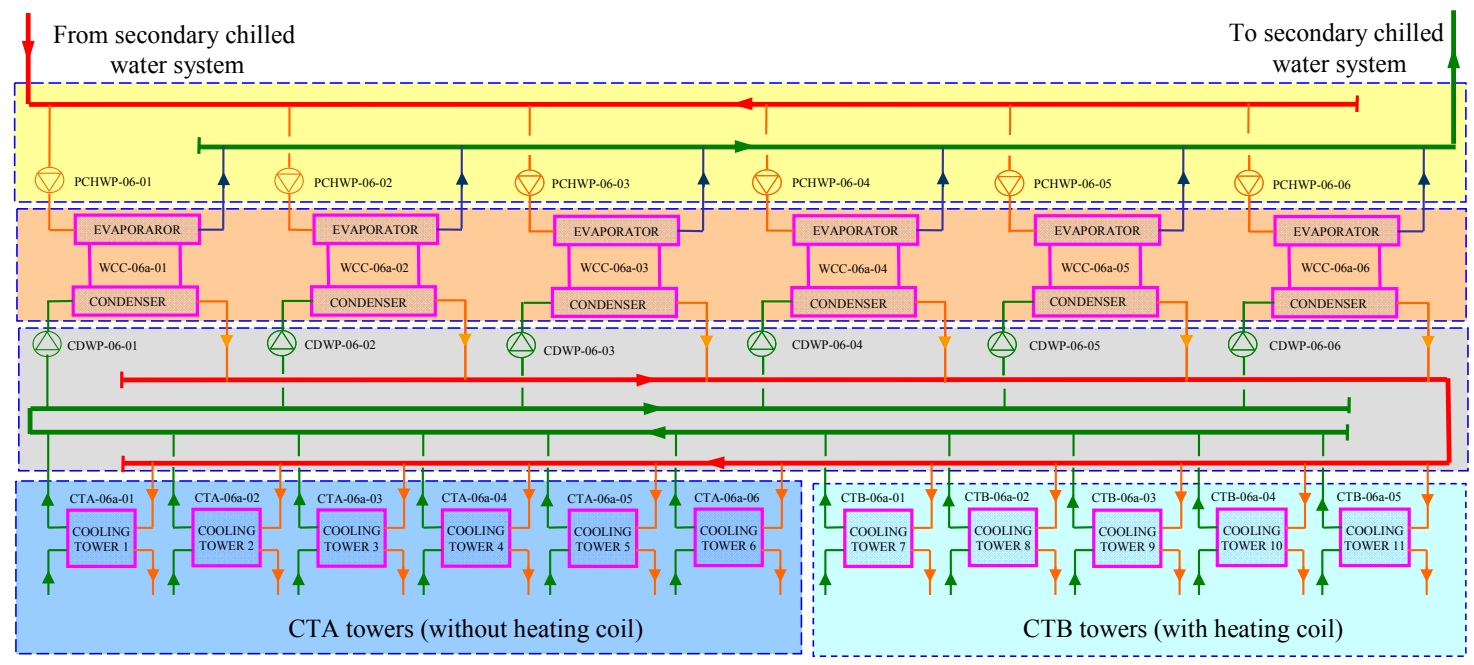

Fig. 1. Schematic of the central cooling water system. 


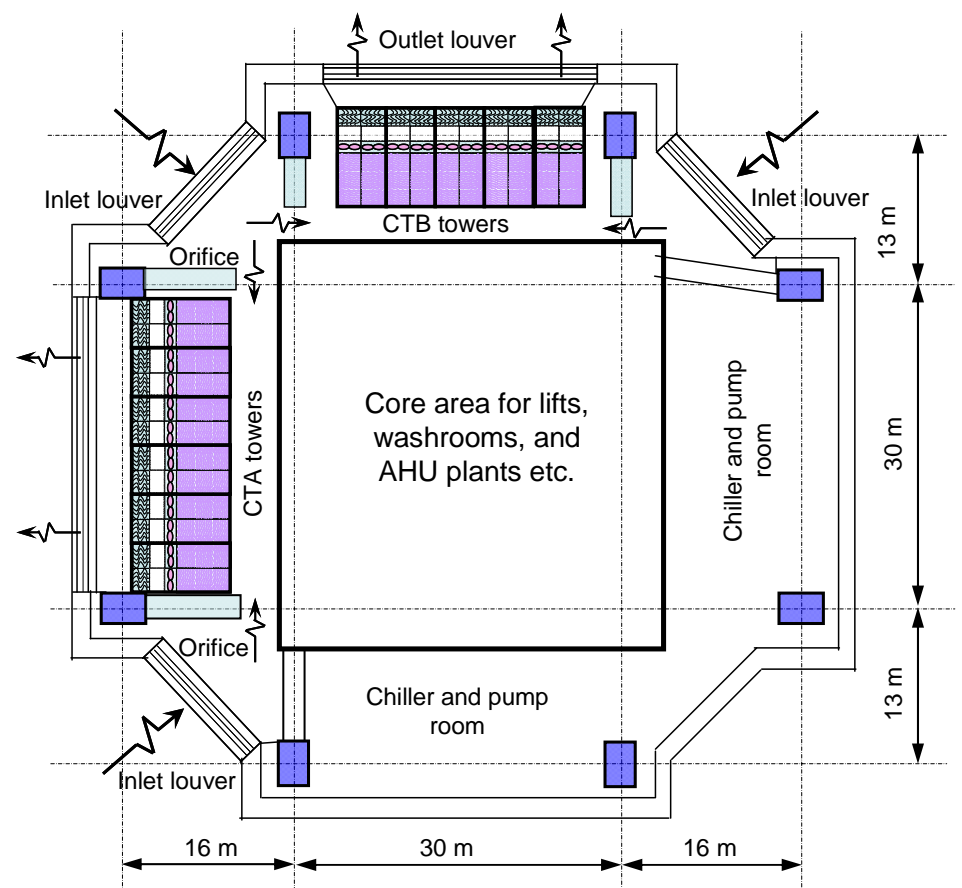

Fig. 2. Layout of the cooling towers at the mechanical floor.

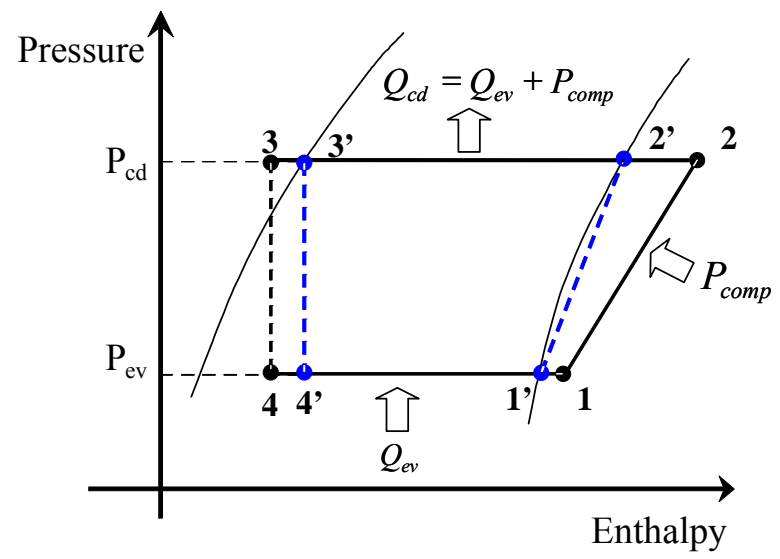

Fig. 3. Schematic of the pressure-enthalpy diagram (actual cycle: 1-2-3-4; fictitious cycle: $1^{\prime}-22^{\prime}-3{ }^{\prime}-4 '$ ). 


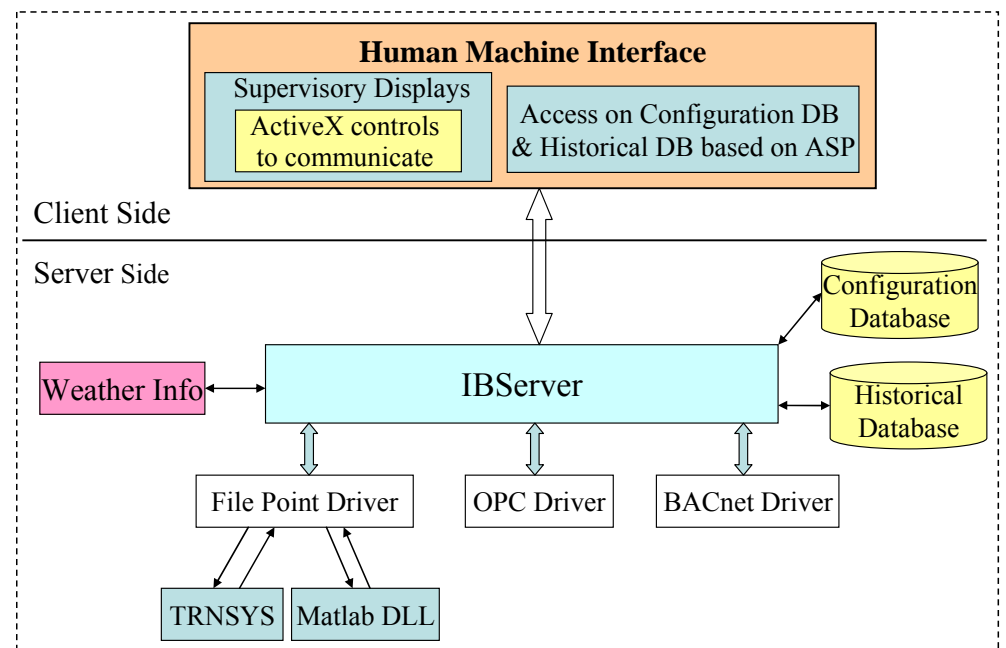

Fig. 4. System architecture of the communication platform based on IBmanager.

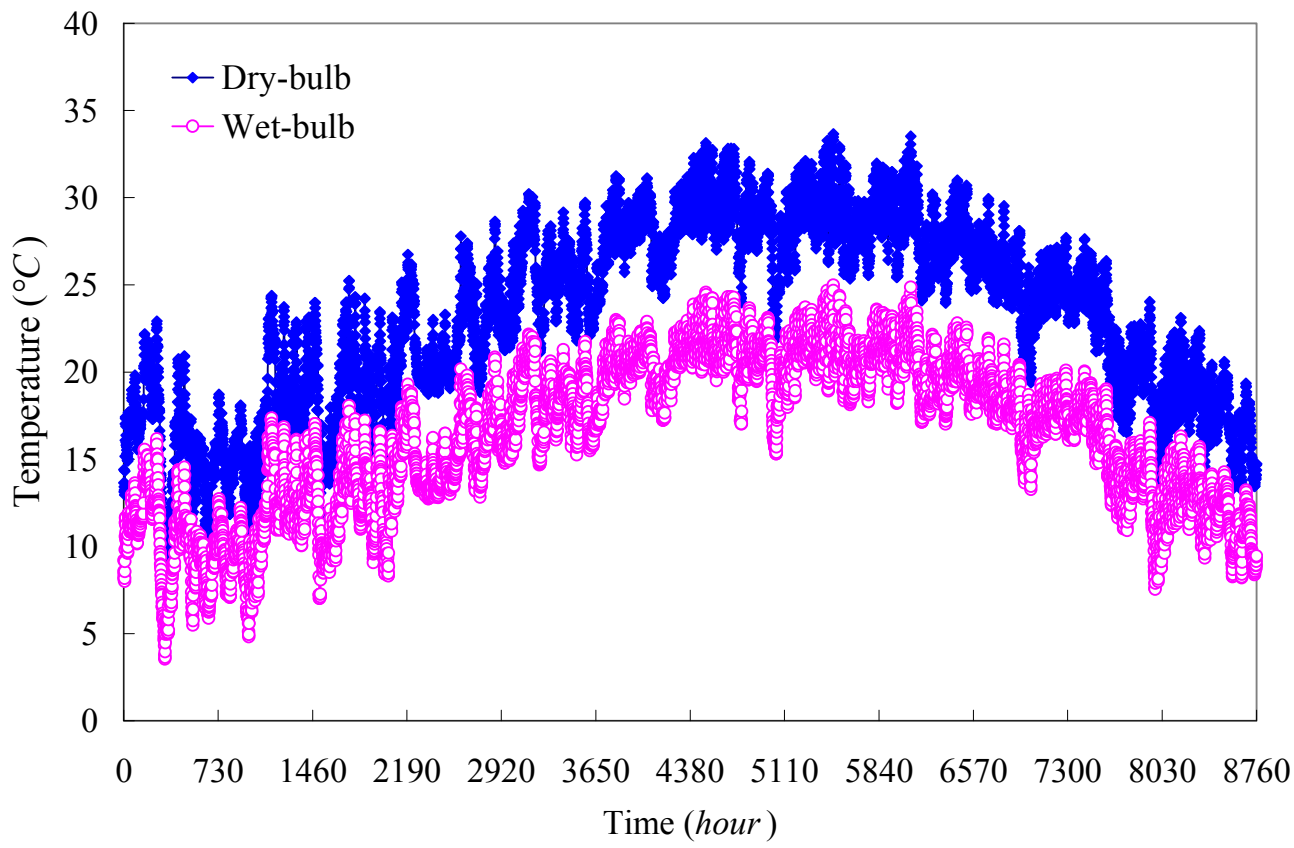

Fig. 5. Profiles of the ambient dry-bulb and wet-bulb air temperatures in the typical year 


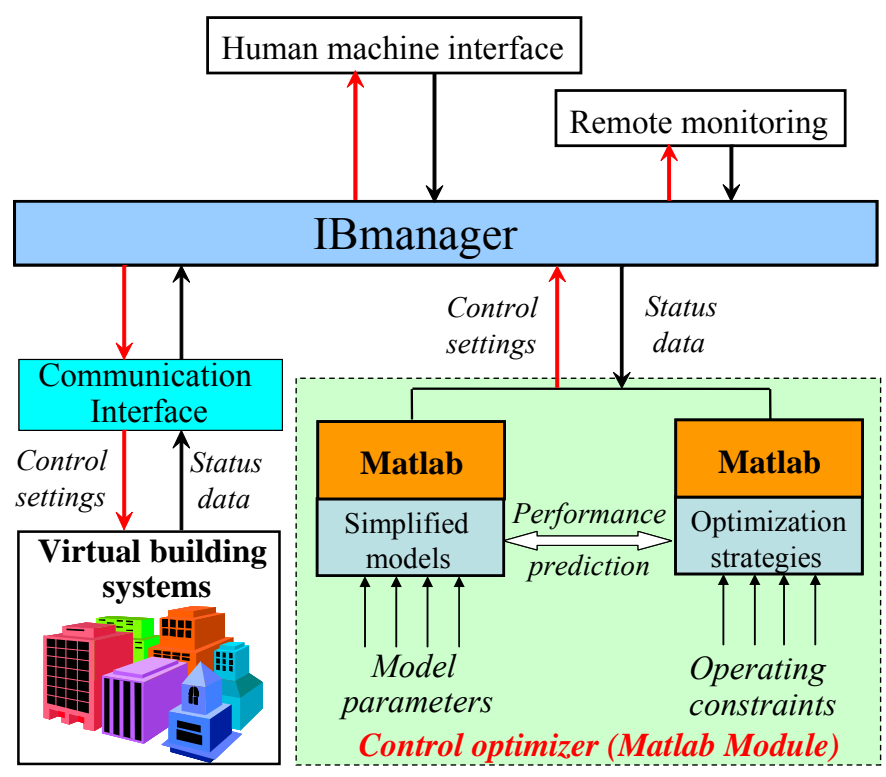

Fig. 6. Overall evaluation platform of the control strategies.

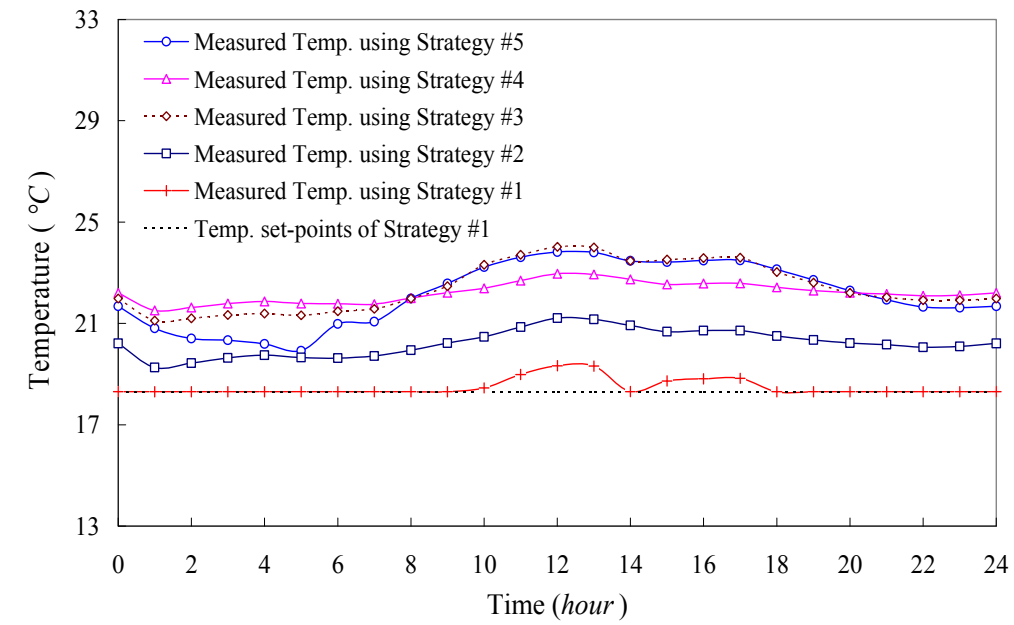

Fig. 7. Online measured water temperatures leaving cooling towers using the settings provided by different strategies in the typical spring day. 


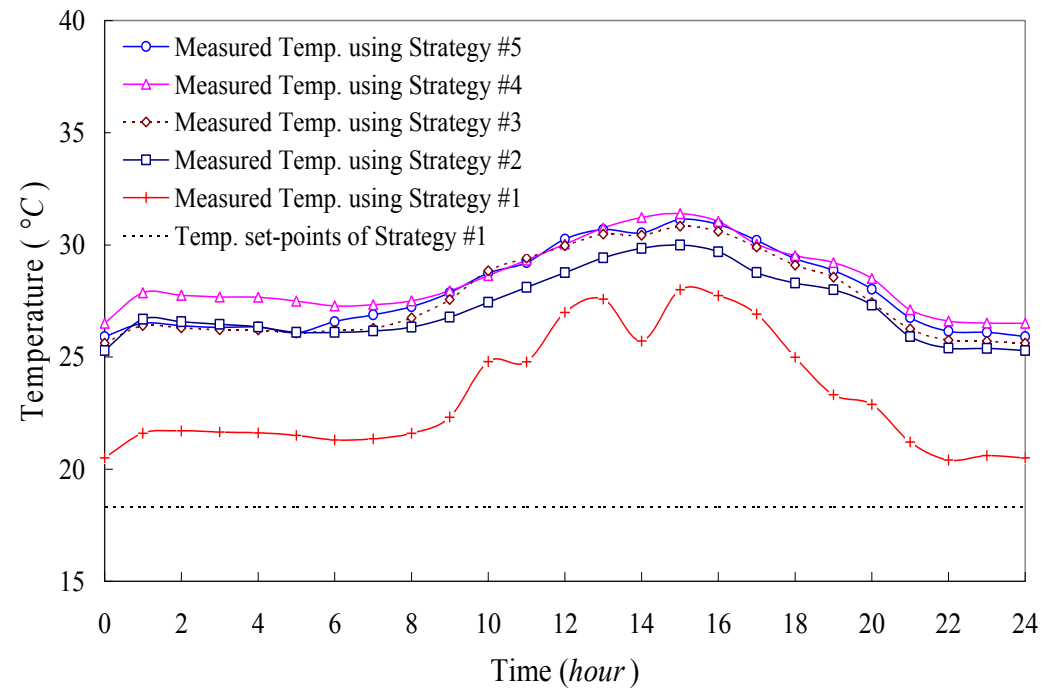

Fig. 8. Online measured water temperatures leaving cooling towers using the settings provided by different strategies in the typical sunny-summer day.

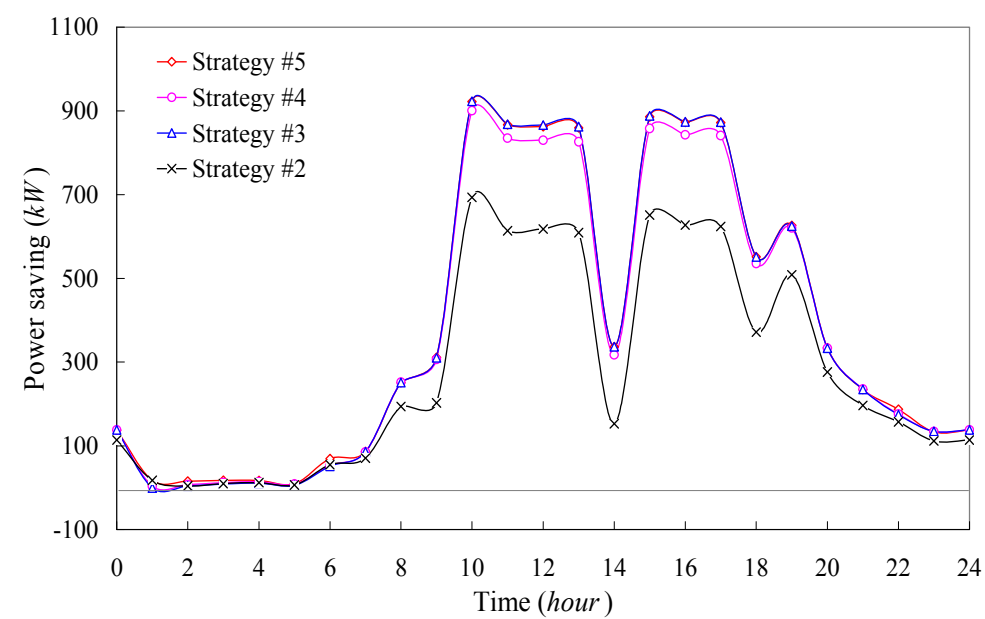

Fig. 9. Savings in measured power consumptions using strategies \#2-\#5 compared with that using strategy \#1 in the typical spring day. 


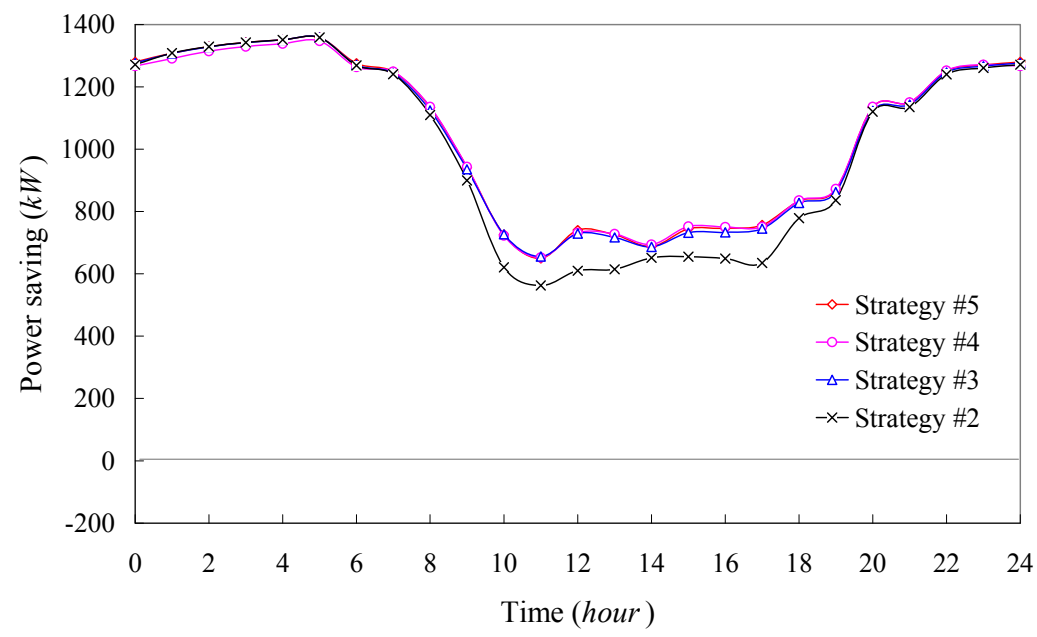

Fig. 10. Savings in measured power consumptions using strategies \#2-\#5 compared with that using strategy \#1 in the typical sunny-summer day. 
Table 1

Identified control settings, predicted power consumption and computational cost as well as online measurements using different control strategies in two typical cases

\begin{tabular}{|c|c|c|c|c|c|c|c|c|c|c|c|c|c|c|}
\hline \multicolumn{15}{|c|}{ Sunny-summer case (online measurements used for control supervision: $T_{d b}=32.61^{\circ} \mathrm{C}, T_{w b}=24.12^{\circ} \mathrm{C}, N_{c h}=6, T_{w, e v, o}=5.5^{\circ} \mathrm{C}, T_{w, e v, i}=9.73^{\circ} \mathrm{C}$ ) } \\
\hline \multirow{2}{*}{$\begin{array}{c}\text { Control } \\
\text { strategies }\end{array}$} & \multicolumn{8}{|c|}{ Control settings, power predicted and computational cost } & \multicolumn{6}{|c|}{ Online measurements } \\
\hline & $\begin{array}{c}N_{C T A} \\
(-)\end{array}$ & $\begin{array}{c}N_{C T B} \\
(-)\end{array}$ & $\begin{array}{c}T_{\text {set }} \\
\left({ }^{\circ} \mathrm{C}\right)\end{array}$ & $\begin{array}{l}\text { Freq } \\
(\mathrm{Hz})\end{array}$ & $\begin{array}{c}W_{c h} \\
(\mathrm{~kW})\end{array}$ & $\begin{array}{c}W_{c t} \\
(\mathrm{~kW})\end{array}$ & $\begin{array}{c}W_{c h}+W_{c t} \\
(\mathrm{~kW})\end{array}$ & $\begin{array}{c}\text { Time } \\
(s)\end{array}$ & $\begin{array}{l}T_{w, c t, i} \\
\left({ }^{\circ} \mathrm{C}\right)\end{array}$ & $\begin{array}{l}T_{w, c t, o} \\
\left({ }^{\circ} \mathrm{C}\right)\end{array}$ & $\begin{array}{l}\text { Freq } \\
(\mathrm{Hz})\end{array}$ & $\begin{array}{c}W_{c h} \\
(\mathrm{~kW})\end{array}$ & $\begin{array}{l}W_{c t} \\
(\mathrm{~kW})\end{array}$ & $\begin{array}{c}W_{c h}+W_{c t} \\
(\mathrm{~kW})\end{array}$ \\
\hline Strategy \#1 & 6 & 5 & 18.30 & 50.0 & --- & 1512 & --- & 0.136 & 31.37 & 27.24 & 50.0 & $5,950.0$ & 1512.0 & $7,462.0$ \\
\hline Strategy \#2 & 6 & 5 & 29.12 & 38.3 & $6,271.4$ & 765.2 & $7,036.6$ & 0.132 & 33.27 & 29.12 & 36.6 & $6,145.0$ & 681.8 & $6,826.8$ \\
\hline Strategy \#3 & 6 & 5 & 30.17 & 33.2 & $6,426.9$ & 529.5 & 6,9 & 0.133 & 34.34 & 30.17 & 31.6 & $6,255.0$ & 469.6 & ,724.6 \\
\hline Strategy \#4 & 6 & 5 & 30.42 & 32.2 & $6,463.7$ & 489.1 & 6,9 & 0.133 & 34.58 & & 30.7 & $6,281.0$ & 433.3 & 4.3 \\
\hline Strategy \#5 & 6 & 5 & 30.47 & 32.0 & $6,472.0$ & 480.6 & $6,952.6$ & 0.152 & 34.64 & 30.47 & 30.5 & $6,287.0$ & 425.6 & 12.6 \\
\hline \multicolumn{15}{|c|}{ Spring case (Online measurements used for control supervision: $T_{d b}=20.76^{\circ} \mathrm{C}, T_{w b}=14.39^{\circ} \mathrm{C}, N_{c h}=4, T_{w, e v, o}=5.5^{\circ} \mathrm{C}, T_{w, e v, i}=9.78^{\circ} \mathrm{C}$ ) } \\
\hline \multirow{2}{*}{$\begin{array}{l}\text { Control } \\
\text { strategies }\end{array}$} & \multicolumn{8}{|c|}{ Control settings, power predicted and computational cost } & \multicolumn{6}{|c|}{ Online measurements } \\
\hline & $\begin{array}{c}N_{C T A} \\
(-)\end{array}$ & $\begin{array}{c}N_{C T B} \\
(-)\end{array}$ & $\begin{array}{r}T_{\text {set }} \\
\left({ }^{\circ} \mathrm{C}\right) \\
\end{array}$ & $\begin{array}{l}\text { Freq } \\
(\mathrm{Hz})\end{array}$ & $\begin{array}{c}W_{c h} \\
(\mathrm{~kW})\end{array}$ & $\begin{array}{c}W_{c t} \\
(\mathrm{~kW})\end{array}$ & $\begin{array}{c}W_{c h}+W_{c t} \\
(\mathrm{~kW})\end{array}$ & $\begin{array}{c}\text { Time } \\
(s)\end{array}$ & $\begin{array}{l}T_{w, c t, i} \\
\left({ }^{\circ} \mathrm{C}\right)\end{array}$ & $\begin{array}{l}T_{w, c t, o} \\
\left({ }^{\circ} \mathrm{C}\right)\end{array}$ & $\begin{array}{l}\text { Freq } \\
(\mathrm{Hz})\end{array}$ & $\begin{array}{c}W_{c h} \\
(\mathrm{~kW})\end{array}$ & $\begin{array}{c}W_{c t} \\
(\mathrm{~kW})\end{array}$ & $\begin{array}{c}W_{c h}+W_{c t} \\
(\mathrm{~kW})\end{array}$ \\
\hline Strategy \#1 & 5 & 5 & 18.30 & 49.1 & $3,293.0$ & 1297.3 & $4,590.3$ & 0.137 & 22.39 & 18.30 & 48.3 & $3,385.0$ & 1243.0 & $4,628.0$ \\
\hline Strategy \#2 & 5 & 5 & 19.39 & 41.3 & $3,374.0$ & 839.0 & 4,2 & 0.137 & 23.49 & 19.39 & 40.8 & $3,460.0$ & 810.5 & $4,270.5$ \\
\hline Strategy \#3 & 5 & 5 & 22.65 & 27.7 & $3,630.5$ & 300.7 & $3,931.2$ & 0.137 & 26.78 & 22.65 & 27.5 & $3,691.0$ & 292.6 & $3,983.6$ \\
\hline Strategy \#4 & 5 & 5 & 21.60 & 31.1 & $3,545.5$ & 402.7 & $3,948.2$ & 0.137 & 25.73 & 21.60 & 30.8 & $3,617.0$ & 391.7 & $4,008.7$ \\
\hline Strategy \#5 & 5 & 5 & 22.55 & 28.0 & $3,622.3$ & 308.7 & $3,931.0$ & 0.175 & 26.68 & 22.55 & 27.7 & $3,684.0$ & 300.5 & $3,984.5$ \\
\hline
\end{tabular}


Table 2

Comparison of online measured and predicted daily power consumptions (chiller + cooling tower) using different control strategies in two typical days

\begin{tabular}{|c|c|c|c|c|c|c|c|c|c|c|c|c|}
\hline \multirow{3}{*}{$\begin{array}{c}\text { Control } \\
\text { strategies }\end{array}$} & \multicolumn{6}{|l|}{ Spring } & \multicolumn{6}{|c|}{ Sunny-summer } \\
\hline & \multicolumn{3}{|c|}{ Online measured } & \multirow{2}{*}{$\begin{array}{c}\text { Predicted } \\
W_{c h}+W_{c t} \\
(\mathrm{kWh})\end{array}$} & \multicolumn{2}{|c|}{ Deviation } & \multicolumn{3}{|c|}{ Online measured } & \multirow{2}{*}{$\begin{array}{c}\text { Predicted } \\
W_{c h}+W_{c t} \\
(\mathrm{kWh})\end{array}$} & \multicolumn{2}{|l|}{ Deviation } \\
\hline & $\begin{array}{c}W_{c h}+W_{c t} \\
(\mathrm{kWh})\end{array}$ & $\begin{array}{l}\text { Saving } \\
(\mathrm{kWh})\end{array}$ & $\begin{array}{c}\text { Saving } \\
(\%)\end{array}$ & & $\begin{array}{c}\text { Dev. } \\
(\mathrm{kWh})\end{array}$ & $\begin{array}{l}\text { Dev. } \\
(\%)\end{array}$ & $\begin{array}{c}W_{c h}+W_{c t} \\
(\mathrm{kWh})\end{array}$ & $\begin{array}{l}\text { Saving } \\
(\mathrm{kWh})\end{array}$ & $\begin{array}{c}\text { Saving } \\
(\%)\end{array}$ & & $\begin{array}{c}\text { Dev. } \\
(\mathrm{kWh})\end{array}$ & $\begin{array}{l}\text { Dev. } \\
(\%)\end{array}$ \\
\hline Strategy \#1 & $63,919.9$ & --- & --- & --- & --- & --- & $112,164.7$ & --- & --- & ---- & --- & --- \\
\hline Strategy \#2 & $57,020.3$ & $6,899.6$ & 10.79 & $55,968.9$ & 1051.4 & 1.84 & $88,312.7$ & $23,852.0$ & 21.27 & $90,456.5$ & $-2,143.8$ & -2.43 \\
\hline Strategy \#3 & $54,506.8$ & $9,413.1$ & 14.73 & $53,790.2$ & 716.6 & 1.31 & $87,431.1$ & $24,733.6$ & 22.05 & $89,804.2$ & $-2,373.1$ & -2.71 \\
\hline Strategy \#4 & $54,750.3$ & $9,169.6$ & 14.35 & $53,920.1$ & 830.2 & 1.52 & $87,385.1$ & $24,779.6$ & 22.09 & $89,868.5$ & $-2,483.4$ & -2.84 \\
\hline Strategy \#5 & $54,438.6$ & $9,481.4$ & 14.83 & $53,687.6$ & 751.0 & 1.38 & $87,307.8$ & $24,856.9$ & 22.16 & $89,752.6$ & $-2,444.8$ & -2.80 \\
\hline
\end{tabular}

Remarks: the deviation in the table is the difference between the power consumption measured from the virtual building system and the power consumption predicted by the control strategies. 